\title{
Imidazolic Copper Metallic Frameworks to Porous Carbon: An efficient Electrochemical Sensor for Determination of Biomoleculles ${ }^{\dagger}$
}

\author{
Padmanaban S. ${ }^{1, *}$, D. Suresh ${ }^{1}$ \\ 1 Department of Medical Nanotechnology, SASTRA University, Tanjore \\ * Correspondence: ayanaravinth96@gmail.com; \\ $\dagger$ Presented at International Conference on Bioengineering for Health and Environment (ICBHE 2020)
}

Received: 5.07.2020; Revised: 10.07.2020; Accepted: 12.07.2020; Published: 15.07.2020

\begin{abstract}
Electrochemical sensing has gained attention owing to its easy analysis and highly efficient outputs. Metal-Organic Frameworks (MOF) derived Nanoporous Carbon (NC) are recently widely used in chemical separation and sensing applications due to its large surface area, thermal and mechanical stability. MOF contains organic linkers (Imidazole) as clusters and inorganic metal (Copper) in the nodes. Zeolitic Imidazole Frameworks (ZIF). In this current work, we deal with the synthesis and characterization of Copper ZIF materials. The synthesized materials were characterized using SEM, PXRD, XPS, TEM, and FTIR. To check the catalytic activity of the carbonised- ZIF, the Glassy Carbon Electrode (GCE) was modified. The modified GCE is used to find out its activity against various biomolecules, such as Dopamine, Ascorbic Acid, Uric Acid, etc. All the results will be analyzed, and the simultaneous detection of biomolecules will also be checked with the modified GCE.
\end{abstract}

Keywords: MOF; CU-ZIF; Electrochemical sensing.

(C) 2020 by the authors. This article is an open-access article distributed under the terms and conditions of the Creative Commons Attribution (CC BY) license (https://creativecommons.org/licenses/by/4.0/).

\section{Funding}

This research received no external funding.

\section{Acknowledgments}

This research has no acknowledgment.

\section{Conflicts of Interest}

The authors declare no conflict of interest. 